\title{
¿Dar la mano o darle cuello? \\ Construcciones metafóricas \\ con sustantivos corporales
}

Alma Rocío Guzmán Herrera María del Refugio Pérez Paredes Ricardo Maldonado

Recebido em: 30 de agosto de 2019 Aceito: 20 de setembro de 2019
Directora de Grupo Educativo CEA, encargado de labores de investigación en lingüística y en educación, elaboración y diseño de talleres de capacitación para profesores.

Contato: roxera2sal4@gmail.com

Universidad Autónoma

Metropolitana (Iztapalapa)

Contato: kukiper@yahoo.com

Profesor-investigador del Instituto de Investigaciones Filológicas de la Universidad Nacional Autónoma de México y profesor invitado del Posgrado en Lingüística de la Universidad Autónoma de Querétaro.

Contato: msoto@unam.mx México 
PALABRAS CLAVE:

frases idiomáticas; partes

del cuerpo; significado

construccional; semántica de marcos

KEYWORDS: idiomatic phrases; body parts;

constructional meaning; frames semantics
Resumen: El verbo dar suele combinarse con sustantivos anatómicos para formar expresiones de interpretación metafórica. En este trabajo intentaremos explicar cómo es que dicho verbo puede construirse con estos sustantivos y qué implicaciones semántico-sintácticas acarrea sus resultados construccionales. El propósito es ir más allá del presupuesto de que se trata de metáforas. Intentaremos explicar este fenómeno policonstruccional desde la confluencia de tres modos de aproximación: la lingüística cosnoscitiva, la gramática de construcciones y la semántica de marcos. Sostenemos que las expresiones con sustantivos anatómicos provienen de la construcción esquemática del verbo dar, la transferencia, que pasa por un proceso de cambio semántico, pero que conserva algunas de las propiedades de la construcción original.

Abstract: The verb to give usually combines with body parts nouns to form expressions of metaphorical interpretation. In this paper, we will try to explain how this verb can be constructed with these nouns and what semantic-syntactic implications its construction results entails. The purpose is to go beyond the presupposition that it is about metaphors. We will try to explain this polyconstruction phenomenon from the confluence of three approaches: cognitive linguistics, construction grammar and frame semantics. We argue that the expressions with body parts nouns come from the schematic construction of the verb to give, the transference, which goes through a process of semantic change, but preserves some of the properties of the original construction. 
¿Dar la mano o darle cuello? Construcciones metafóricas con sustantivos corporales Alma Rocío Guzmán Herrera

\section{INTRODUCCIÓN}

Que podamos hablar sobre las características del verbo dar y de por qué es posible que sea preferido por los hablantes para generar nuevas expresiones y nuevos significados es consecuencia de la riqueza semántico-sintáctica que confiere a la noción de transferencia. La multifuncionalidad de dar puede ser vista como consecuencia de un proceso de desemantización que lo convierte en un verbo ligero, en cuyo caso tiene aportación mínima y el sustantivo lleva la mayor carga informativa. En dar un golpe 'golpear' el sustantivo es informativo, mientras que dar solo introduce la noción de acción procesal. Lo mismo sucede con dar un paseo que equivale a 'pasear' (Alonso Ramos, 2004, 17-19). Cuando el verbo es ligero se constituye como verbo de "soporte" sin mayor aportación semántica. La pregunta es si ese análisis es adecuado para dar cuenta de una notable cantidad de construcciones en que el verbo dar se combina con partes del cuerpo como las que se ofrecen en (1):

(1a) Hoy nadie puede darle la espalda a la globalización. Darle la espalda a la globalización no hace a un país mejor. [CREA. 1998. México. Oral. Cámara de senadores.]

(1b) No hay que darle las nalgas a un machista... a ver si no necesita a una mujer. [Google. 16/07/2017].

(1c) Sus hijos y hermanos que acudían a darle una mano[CREA. 1991. México. Chao Ebergenyi, Guillermo. De los Altos. Diana]. 
(1d) El trabajo fundamental de las comisiones de Estudios Legislativos es darle cuerpo jurídico a las opiniones de las comisiones. [CREA. México. Oral. Cámara de senadores.]

(1e) Telehit decide darle cuello a estos programas [Google. 16/07/2017].

Todas estas expresiones tienen un sentido figurado. En (1a) darle la espalda a la globalización quiere decir 'negarle apoyo a alguien', o en (1b) darle las nalgas a un machista quiere decir 'entregarse sexualmente', en tanto que en (1c) darle una mano significa 'ayudar, apoyar' mientras que en (1d) darle cuerpo jurídico a las opiniones significa 'darle forma'. Finalmente en (1e) darle cuello significa 'matar a alguien o eliminar algo'. Notable en estos ejemplos es que la noción de dar como evento de transferencia sigue recuperándose. Como notable es que no es el sustantivo sino la construcción completa lo que aporta el significado figurado de estas expresiones. Todo parece indicar que el análisis de dar como verbo ligero no aporta el mejor análisis. En este trabajo intentaremos explicar cómo es que el verbo dar puede construirse con distintos sustantivos del dominio corporal y qué implicaciones semántico-sintácticas acarrea sus resultados construccionales. El propósito es ir más allá de asumir la existencia del evidente valor metafórico que revisten estas expresiones. Intentaremos explicar este fenómeno policonstruccional desde la confluencia de tres modos de aproximación: la lingüística cognoscitiva (Langacker, 1987 y 1991), la gramática de construcciones (Goldberg, 1995; 2003; 2006) y la semántica de marcos (Fillmore, 1982;1985). 
¿Dar la mano o darle cuello? Construcciones metafóricas con sustantivos corporales

Es bien sabido que el dominio corporal provee una amplia gama de posibilidades de creación de expresiones nuevas en las lenguas del mundo. El cuerpo humano es considerado un dominio cognitivo básico que funge como fuente para la creación de diversos significados de carácter metafórico. La tipología lingüística ha evidenciado lo cognitivamente importante que es este dominio y ha seńalado la productividad que tiene para generar estructuras y significados nuevos; por ejemplo, se ha mostrado cómo los sustantivos corporales se proyectan de manera regular y universal hacia el dominio de la espacialidad, dando lugar a la creación de morfemas espaciales y preposiciones (Svorou, 1994; De León, 1992; Heine, Claudi y Hünnemeyer, 1991; y muchos otros).

\section{Presuplestos teóricos}

El hecho de que los sustantivos corporales puedan proyectarse semánticamente para codificar significados distintos a lo anatómico no sólo obedece a su carácter cognitivamente básico, sino a que conforman una serie de marcos semánticos (Fillmore, 1982), que hacen referencia fundamentalmente a aspectos físicos, pero también a aspectos sociales y culturales. Por marco semántico (Fillmore, 1982) se entiende cualquier sistema de conceptos vinculados entre sí, de tal manera que para entender uno de ellos, es necesario comprender la estructura completa del sistema del que ese concepto forma parte. Visto así, el significado de los elementos léxicos está organizado de modo que, al emplear un elemento en un discurso, se 
activan diversos valores asociados a ese lexema. Dentro del marco semántico de un elemento léxico se encuentran todas sus asociaciones semánticas, es decir, sus valores polisémicos, sus derivados léxicos, su valencia sintáctica y semántica, sus significados metafóricos, etcétera.

En este sentido, cada sustantivo anatómico implica un marco semántico en el que los significados se organizan a partir de aspectos básicos, como por ejemplo, los rasgos físicos (su localización en el cuerpo como entidad holística, su forma, su tamańo y su función), y se conectan con aspectos menos básicos, como los generados social y culturalmente, o con valores asociados a escenas que el ser humano experimenta en su vida cotidiana. Los marcos semánticos activados por los distintos sustantivos anatómicos subyacen en todas sus proyecciones.

El cuerpo humano implica un conjunto de elementos que se distinguen por poseer propiedades que aluden a lo concreto, visible, tangible. Las partes del cuerpo pueden incluir otras partes, por ejemplo, el brazo implica el antebrazo, el codo, la mano, y la mano implica a su vez los dedos (Langacker, 1987). Además, constituyen entidades hasta cierto punto discretas, en el sentido de que podemos identificar dónde comienza y termina una parte. Así también, entre ellas existe una asimetría, puesto que algunas resultan más prominentes que otras, por ejemplo, la cabeza, la cara, la frente y las manos son más prominentes que la mayoría de los órganos internos. Las partes del cuerpo conllevan relaciones topológicas, las cuales hacen referencia a conceptos o relaciones de carácter espacial (MacLaury, 1989; De León, 1991 y 1993; Levinson, 1996a y 1996b; Vandeloise, 1986; entre otros), tales 
¿Dar la mano o darle Cuello? Construcciones metafóricas con sustantivos corporales Alma Rocío Guzmán Herrera

como la orientación en el eje vertical (superior/inferior), en el eje horizontal (adelante/atrás), en el lateral (izquierda/derecha), o bien, nociones como soporte, contención (interioridad), contigüidad, contacto y movimiento. Otra de sus características es que constituyen entidades poseídas inalienablemente, es decir, aluden a una relación inherente o íntima (Seiler, 1983; Heine, 1997) e integral (Chappel y McGregor, 1996, apud Heine, 1997) con el cuerpo como totalidad. El carácter inalienable de los sustantivos de este dominio resulta fundamental ya que tiene un efecto semántico-sintáctico en las expresiones en las que aparecen. Las partes del cuerpo, además, poseen una función sustancial que permite al cuerpo desempeñarse de manera apropiada. Todos estos elementos forman parte de la semántica de marcos del dominio corporal, más valores sociales y culturales, así como escenas de la vida cotidiana.

\subsection{Estudios sobre el cuerpo y sus partes}

Los estudios tipológicos sobre partes del cuerpo se han centrado en el léxico y en los morfemas derivados de éste y, en general, no dan cuenta de las frases idiomáticas formadas a partir del léxico anatómico. Al respecto, la fraseología ha intentado caracterizar estas expresiones según su grado de idiomaticidad (opacidad semántica y fijación sintáctica). Recientemente, con los avances en teoría de la metáfora, desde la lingüística cognitiva, se han llevado a cabo estudios de estas expresiones con el propósito de explicar cómo se construye su significado metafórico. Particularmente hay estudios 
específicos en los que aparece el sustantivo mano como parte de frases idiomáticas (Márquez Linares, 1998; Márquez y Moreno, 1999; CharterisBlack, 2001; Julià Luna y Paz Afonso, 2012; Vuksan, 2016, entre otros), las cuales han sido abordadas fundamentalmente como metáforas o metonimias, de manera que dichos estudios se centran en los mecanismos de extensión semántica del sustantivo mano hacia distintos dominios, en los tipos de metáfora y metonimia que desencadena y en el análisis contrastivo entre metáforas con mano en distintas lenguas, para determinar los grados de equivalencia entre unidades fraseológicas.

\section{Propuesta analítica}

En este trabajo pretendemos analizar la estructura semántica y sintáctica de estas expresiones desde aproximaciones construccionistas, tanto desde la gramática cognoscitiva (Langacker, 1987; 1991) como desde la gramática de construcciones (Golberg, 1995; 2003; 2006). Una construcción es entendida como una unidad forma-significado con distintos grados de elaboración. Hay construcciones básicas y esquemáticas que dan lugar a otras más específicas a partir de diversos mecanismos sintáctico-semánticos. Sostenemos la idea de que de una construcción madre hereda sus propiedades a otra serie de construcciones más específicas, construcciones de nivel bajo, las cuales responden a extensiones semántico-sintácticas que se establecen a partir de relaciones metonímicas. En nuestro análisis ofreceremos una explicación que parte de 
¿Dar la mano o darle cuello? Construcciones metafóricas con sustantivos corporales Alma Rocío Guzmán Herrera

María del Refugio Pérez Paredes

Ricardo Maldonado

la existencia de un esquema construccional básico: todas las expresiones de (1) tienen su origen en una construcción madre de la cual heredan rasgos semántico-sintácticos fundamentales. La construcción madre de la que partiremos es la construcción de transferencia, según la cual un objeto pasa del dominio fuente a un dominio meta (Langacker, 1987; Goldberg, 1995; 2003; Maldonado, 2002). Resaltaremos que las restricciones al esquema de transferencia son introducidas por el sustantivo anatómico cuyo significado propicia tanto una lectura literal, como una interpretación metafórica. El tema, formalizado en la construcción como objeto directo, impone en la construcción no sólo sus propiedades semánticas sino todo su marco conceptual (frame) y este determina su significado figurado. El verbo dar, por su parte, sufre procesos de desemantización, ya que no todas sus propiedades pueden ser activadas con una parte corporal que pierde propiedades físicas y proyecta significados figurados. Fundamental, sin embargo, es que el verbo dar preserva su estructura esquemática de transferencia. Se pasa de una transferencia canónica a una transferencia limitada o modificada por la introducción de las propiedades de las extensiones que se desprenden del sustantivo anatómico involucrado.

La existencia de expresiones como las de (1) invitan a plantearse las siguientes preguntas: ¿Por qué la construcción de transferencia permite la inserción de un sustantivo corporal? ¿Qué agrega el sustantivo corporal a la expresión? ¿Qué rasgos del significado de la construcción madre se mantienen y qué otros se modifican? ¿Qué efectos formales provoca esta operación? ¿Le ocurre algo a nivel semántico al verbo dar que permite la 
expresión metafórica? Intentaremos resolver todas estas preguntas a lo largo de este trabajo.

Como se verá en el análisis, las expresiones figuradas con dar + sustantivo anatómico pueden explicarse a partir de un esquema construccional básico del cual heredan rasgos semántico-sintácticos y modifican el significado original debido al frame del léxico anatómico.

\section{Construcción de transferencia}

Partimos de que todas las expresiones de (1) provienen del esquema básico de la construcción de transferencia que a continuación explicamos en (2):

(2a) Fernando le dio flores a María

(2b) La secretaria le envió el paquete al presidente

(2c) La mujer le contó una historia a su sobrino

El significado básico de estas expresiones es de transferencia. Una transferencia ocurre cuando una entidad prototípicamente humana envía un objeto (concreto o abstracto), hacia el dominio de otro participante, el cual funge como nuevo poseedor del objeto, como se puede ver en los ejemplos de (2) en donde Fernando (2a), secretaria (2b) y mujer (2c) transfieren flores, el paquete y una historia respectivamente al dominio de María, el presidente y su sobrino. La construcción de transferencia responde a la representación esquemática en (3): 
¿Dar la mano o darle cuello? Construcciones metafóricas con sustantivos Corporales Alma Rocío Guzmán Herrera

María del Refugio Pérez Paredes

Ricardo Maldonado

\section{(3) 'XCAUSA que YRECIBAZ'}

En donde un agente, el sujeto, transfiere el contenido del tema (objeto directo), al domino del receptor, codificado como objeto indirecto o dativo.

(4) Agente

Fernando

Sujeto
Tema

le dio

Objeto Directo
Receptor

flores a su novia

Objeto Indirecto (dativo)

La Figura 1 muestra esquemáticamente la construcción de transferencia: un objeto es trasladado del dominio del agente al dominio del receptor. La línea curva punteada indica que los dos círculos negros corresponden a la misma entidad. La esfera de la izquierda representa el dominio del agente y la esfera de la derecha representa el del receptor.

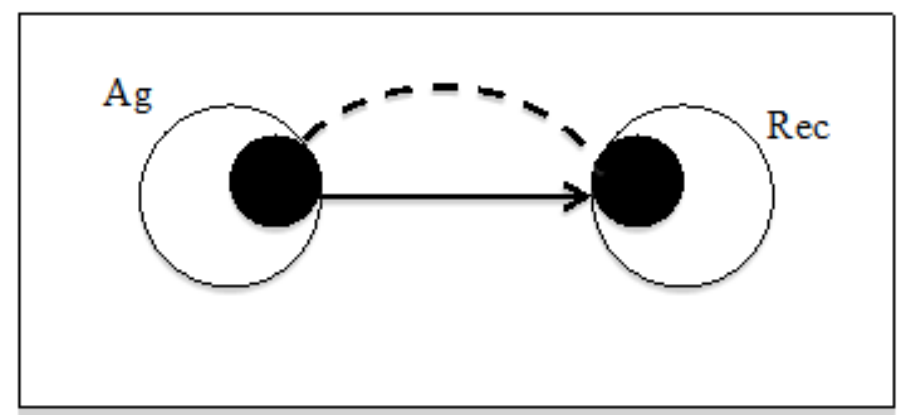

Figura 1: Esquema de la construcción de transferencia 


\section{Sentidos eXtendidos. Transferencias debllitadas}

Sobre la construcción de transferencia el objeto directo impone especificaciones que determinan tanto una lectura literal como una figurada. Empezaremos el análisis con ejemplos de las expresiones dar el pecho/darle el pecho/dar pecho que se muestran en los ejemplos de (5):

(5a) ¿Le vas a dar el pecho o le vas a dar biberón? [Google. 16/07/2017].

(5b) ¿Has decidido no darle el pecho a tu bebé? Darle el calostro sería una buena opción. [Google. 16/07/2017].

(5c) Y tú, ¿alimentaste a tu bebé? Sí le di pecho por 8 meses. [Habla espontánea, CDMX. 2017]

En estas expresiones convive el significado literal de transferencia concreta con el extendido en que se hace referencia al acto de "amamantar". De la construcción de transferencia se hereda que un agente provoque que una entidad (la leche contenida en el pecho) pase a la esfera de un receptor (el bebé), quien se ve afectado positivamente al consumir la leche que recibe. Formalmente la estructura se mantiene, en los ejemplos de (5a, b). Tanto el significado de base como el figurado están presentes dada la natural relación continente/contenido entre pecho y leche. Resalta el valor activo del marco conceptual (frame) de pecho: fuente de alimento materno que nace de una obvia relación metonímica en que el contenido es tomado por el contenedor. Ya sin artículo la expresión dar pecho conforma una construcción fija en que el sustantivo es genérico y no admite pluralidad, 
¿Dar la mano o darle Cuello? Construcciones metafóricas con sustantivos corporales Alma Rocío Guzmán Herrera

ni modificación: *yo le doy (los) pechos a mi bebé, ??ya no le dan pecho alimenticio. Lo interesante es que como construcción ya sólo acepta el sentido figurado de amamantar.

La funcionalidad asociada a cada parte del cuerpo determina el tipo de extensiones que genera la construcción. Así como el pecho activa "amamantar", la operacionalidad de la mano genera sus propias extensiones. Los usos figurados de $(6 b, c)$ que se desprenden de $(6 a)$ :

(6a) Cuando atravesemos la calle, es muy importante que me des la mano. [Habla espontánea. CDMX. 2017].

(6b) El Papa quería darle una mano a Castro, a ese "burgués", como lo definió el rey de los industriales italianos, Gianni Agnelli [CREA.1996. México. Proceso].

(6c) ...la Virgen de Guadalupe, San Francisco de Asís, la Generala de Zapopan, los milagros de San Juan de Los Lagos, Santa Gertrudis, los agraristas, Santa Eduviges y su rancho que allá, colina abajo, aparecía desnudo de un trigal que ya debería estar sembrado para esas alturas de la primavera de 1927, sembrado por él y sus hijos y hermanos que acudían a darle una mano; y dónde estaba su mujer que no la veía por el corral, echándole maíz a las gallinas...[CREA. 1991. Chao Ebergenyi, Guillermo. De los Altos. Diana].

En (6a) el significado es literal; en cambio, en los ejemplos de (6b, c) el significado es figurado, dar la mano quiere decir 'ayudar'. De la 
construcción de transferencia se mantiene que una parte del cuerpo (mano) pasa al dominio de un receptor, en términos de contacto. Formalmente, la estructura se conserva; el sustantivo anatómico se fija en singular con determinante. En cambio en $(6 b, c)$ un agente provoca una afectación positiva en un receptor, sin que haya una entidad transferida. Formalmente la estructura se conserva, el sustantivo se fija en singular definido (la mano) o indefinido (una mano). Emerge la lectura de "ayuda", gracias al valor instrumental mano y a las nociones de agentividad y afectación del receptor. Se pierde la noción de control ejercida por el receptor en la transferencia literal, pero se preserva la noción de afectación impuesta en el receptor. Mientras el frame de mano aporta la noción de inalienabilidad y de vínculo interpersonal, como en $(6 a)$, en $(6 b, c)$ el valor instrumental activa la extensión a la noción de 'ayuda'.

Por irónico que pueda parecer, también la funcionalidad de la parte corporal justifica las extensiones de los ejemplos de (7):

(7a) Nunca me dijeron que estudiar derecho significaba darle las nalgas al jefe [Google. 16/07/2017].

(7b) No hay que darle las nalgas a un machista... a ver si no necesita a una mujer [Google. 16/07/2017].

Aquí los usos sólo son figurados. Si bien efectivamente la parte física puede ser puesta a disposición del otro, domina la lectura figurada. El hecho de que no se trate de una extremidad bloquea la lectura literal. El 
significado metafórico hereda de la transferencia la relación entre un agente y una entidad afectada positivamente. Se mantiene la noción de trayectoria porque hay acercamiento/proximidad corporal del sujeto hacia el objeto indirecto. Dado el carácter inalienable de la parte corporal, el receptor no establece posesión del objeto transferido pero si contacto, y con ello se activan las nociones sexuales asociadas a ella. El frame de nalgas restringe, de cierta manera, al verbo dar en cuanto a la noción de transferencia y la convierte en una transferencia parcial. Pero el marco conceptual que se activa es complejo. En primera instancia dar las nalgas significa entregarse sexualmente, pero en esa entrega está también inferida la pérdida del honor. Quien da las nalgas deja de respetarse a sí mismo, se corrompe, se degrada a cambio de algo. De manera que hay dos extensiones, la más próxima a la lectura literal es aquella en que se entrega el cuerpo en forma sexual; la más distal, no presupone la entrega de la parte corporal, pero sí la del honor. Da las nalgas el político corrupto que no es fiel a sus principios, como las dan también quienes entregan el cuerpo a cambio de algo. La entrega del político constituye una extensión metonímica de la entrega corporal. El alto nivel de involucramiento del donador con el receptor se codifica con la duplicación del dativo mediante la presencia del clítico correferencial le (Maldonado, 2002). El sustantivo anatómico en plural y con determinante definido licencia la lectura metonímica de que la parte corporal representa el cuerpo todo. Es imposible decir * le di la nalga al jefe, o ${ }^{*}$ le di nalgas al jefe. La construcción implica dos procesos metonímicos: primero la parte corporal por el todo, nalgas proyecta sexualmente a todo el cuerpo; en 
segunda instancia la entrega sexual implica la pérdida del honor. Como siempre sucede, una vez establecida la metonimia no es necesario que se active la física. Dar las nalgas se asemeja a dar pecho y dar la mano en cuanto a que el objeto transferido impone las características de la construcción e impone la vía de desemantización del verbo dar. El verbo dar tiene la fuerza de la construcción de transferencia 'dar/transferir algo a alguien' pero en estas construcciones las extensiones están determinadas por los rasgos funcionales de las partes del cuerpo en cuestión. Sólo se puede transferir o dar lo que el marco conceptual del sustantivo de la parte del cuerpo licencia. La Figura 2 representa el esquema de la construcción de transferencia debilitada que explicamos en los ejemplos (5 a 7). Se trata de una transferencia, debilitada, parcialmente desemantizada, ya que más que transferirse el objeto en sí, se pone a disposición del receptor el frame que involucra la parte corporal. En la Figura 2, la esfera grande de la izquierda representa al agente formalizado sintácticamente como sujeto; la esfera de la derecha representa al receptor formalizado como objeto indirecto o dativo. Los círculos pequeños representan el tema u objeto transferido, en estos ejemplos, 'el pecho', 'la mano' y 'las nalgas'. Mientras la parte del cuerpo en sí refleja la lectura literal, aquella que abre las lecturas metafóricas depende de la activación de los marcos conceptuales(frames) correspondientes. 


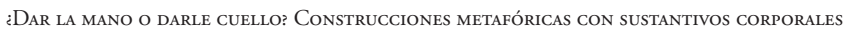
Alma Rocío Guzmán Herrera

María del Refugio Pérez Paredes

Ricardo Maldonado

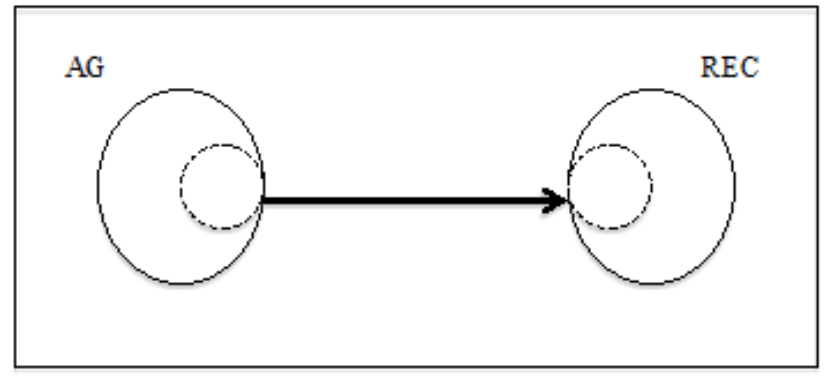

Figura 2: Esquema de construcción de transferencia debilitado

Una precisión es necesaria: en general los verbos de transferencia aceptan un significado genérico cuando no aparece el receptor explícito, pero es evidente que hay un beneficiario implícito; por ejemplo, dar clase, vender seguros, enviar mensajes implican necesariamente un receptor. Lo interesante de las representaciones genéricas sin receptor es que cuando existe una extensión metafórica tales representaciones sólo licencian la lectura figurada, nunca la literal: dar la mano, significa "ayudar", de la misma manera que dar las nalgas significa "ceder sin escrúpulos". La Figura 3 representa la construcción de estos significados genéricos, la esfera de la izquierda corresponde al agente/ sujeto, mientras que la esfera punteada de la derecha representa al receptor implícito; el círculo pequeño representa más que al objeto en sí, a su marco conceptual, el cual licencia los significados figurados. 


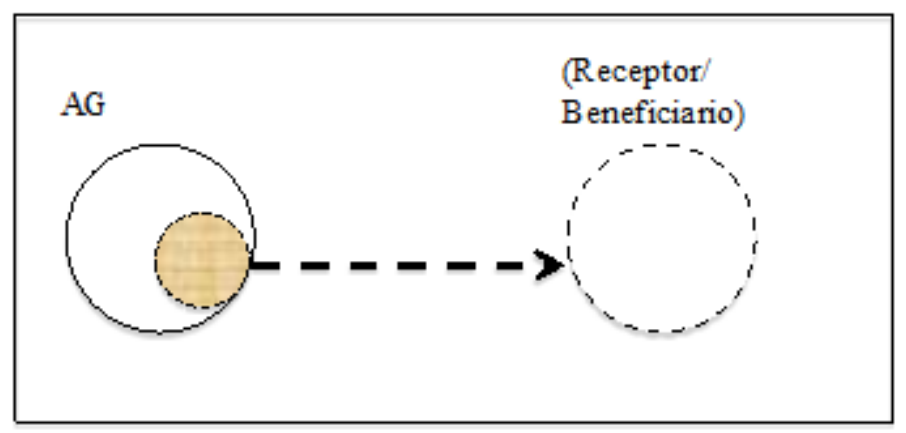

Figura 3: Significado figurado con base en frames

\section{IMPOSICIÓN DE ESTRUCTURA}

Hay otras maneras de debilitar la transferencia. Una de ellas es dejar que la interacción entre agente y receptor sea directa. Esto hará que la afectación sea explícita, como se ve en los ejemplos de (8):

(8a) "mi obligación será emplear todo el tiempo que me dé Dios de vida en el cargo, para intentar la reconciliación de la ciudad consigo misma, para darle cuerpo al alma de una ciudad que se encuentra lastimada, herida”. [CREA. 1997. México. Proceso].

(8b) El trabajo fundamental de las comisiones de Estudios Legislativos es darle cuerpo jurídico a las opiniones de las comisiones[CREA. Oral. Cámara de Senadores].

En estos ejemplos observamos que el significado es metafórico también. En (8a) el significado es "darle forma, estructura, organización a la ciudad" 
¿Dar la mano o darle cuello? Construcciones metafóricas con sustantivos corporales Alma Rocío Guzmán Herrera

y en (8b) el significado es "darle forma, estructura u organización jurídica a las opiniones de las comisiones"; es decir, expresarlas de manera jurídica. De la construcción de transferencia se hereda que un agente provoca una afectación positiva en otra entidad, en (8a) es la ciudad, en (8b) son las opiniones de las comisiones; se pierde la noción de trayectoria, no hay una entidad que se traslade de un dominio a otro, pero sí una fuerza que permite la reconfiguración de la estructura del receptor, que deja de ser un beneficiario y se convierte en un objeto modificado. Este receptor, se acerca más a un paciente; formalmente la estructura se conserva, el sustantivo se fija en singular sin determinante, no se puede decir *darle cuerpos $/ *$ darle los cuerpos/*darle el cuerpo jurídico(s) a las opiniones de las comisiones. El receptor aparece duplicado mediante la presencia del clítico correferencial de dativo le. La imposibilidad de usar determinantes refleja por una parte que se trata de una estructura fija y, por la otra, que la parte corporal no hace referencia a un objeto sino a su marco conceptual. Cuerpo remite a forma, a configuración y a consistencia, rasgos asociados al marco conceptual de Cuerpo, no al cuerpo en sí. En virtud de que dar cuerpo es ya una construcción, lo que ahora gana relieve es el receptor que es modificado por el complejo verbal dar cuerpo. Dicho relieve hace que el receptor se reinterprete como objeto afectado. Si bien se trata de un caso más desemantizado de dar, no se puede afirmar que opere como verbo ligero. Dar cuerpo no corresponde a cuerpear, como dar un paseo corresponde a pasear. La noción de transferencia sigue operando de manera tal que sí se le impone "cuerpo" (metonímicamente forma) al receptor. 
La Figura 4 esquematiza estos ejemplos, la esfera de la izquierda representa al agente/sujeto, la esfera de la derecha representa el foco de la estructura que es ahora un beneficiario en quien recae la acción. La flecha representa la fuerza que se ejerce para transformar al beneficiario. Ya no hay una transferencia concreta; lo que se transfiere es una energía, una fuerza que modifica en términos funcionales y organizacionales al beneficiario. Es por ello que sugerimos que hay un debilitamiento semántico del verbo dar, lo que se transfiere es una energía transformadora con las propiedades del objeto, pero no un objeto en sí. De la forma caótica del receptor (la forma punteada en la Figura 4), la energía que se transfiere impone una configuración ordenada (el círculo en líneas gruesas).

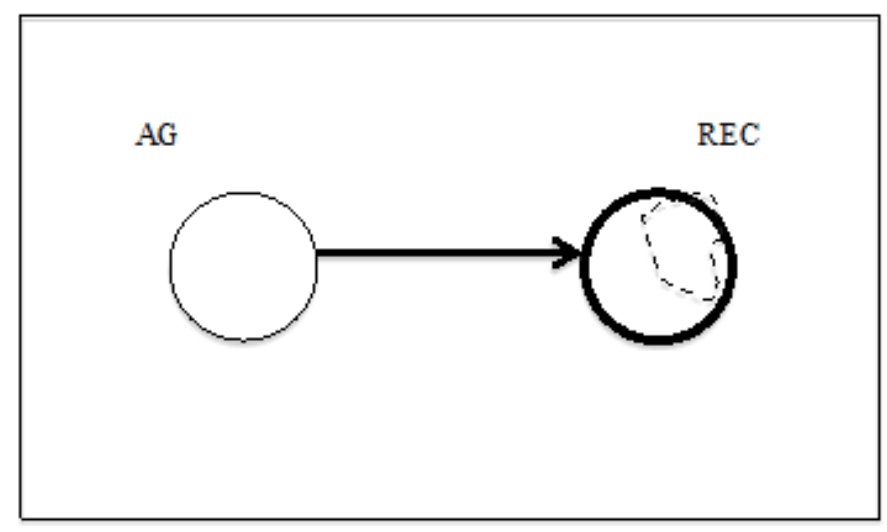

Figura 4: Dar cuerpo. Transferencia con foco en el receptor

La transferencia tiene una connotación más abstracta. El hecho de que se imponga un cambio de estado en el receptor permite que la construcción vaya tomando las características de la Dinámica de Fuerzas (DF) (Talmy, 1985), 
¿Dar la mano o darle cuello? Construcciones metafóricas con sustantivos corporales Alma Rocío Guzmán Herrera

María del Refugio Pérez Paredes

Ricardo Maldonado

como será evidente en la siguiente batería de ejemplos. El sustantivo de referencia anatómica aparece impuesto también en el receptor, como se ve en (9):

(9a) Júntame a toda la raza para darle cuello a este cabrón [Google. 16/07/2017].

(9b) Le dieron cuello en el examen [Google. 16/07/2018].

En estos ejemplos el significado también es metafórico: darle cuello significa "eliminar", "sacar de la jugada", "dejar fuera a alguien”, por ejemplo en (9a) es "eliminar al susodicho" y en (9b) el significado es "reprobar a alguien". ¿Cómo es esto posible? De la estructura de transferencia se hereda que una entidad activa-agentiva provoca una afectación negativa en un receptor. Al igual que en los ejemplos de (8), el foco está en el receptor. Se pierde la idea de trayectoria. No hay una entidad que se traslade sino más bien una fuerza que emana desde el agente y repercute en el receptor, el cual tiende a comportarse más como un paciente. Se pierde totalmente la idea de control del receptor sobre el objeto. Formalmente la construcción es igual a dar cuerpo, pues el sustantivo se fija en singular y no aparece ningún determinante, lo que nos permite comprobar un mayor grado de fijación de la construcción, no es posible decir ${ }^{*}$ le dieron el cuello/ ${ }^{*}$ le dieron los cuellos/ ${ }^{*}$ le dieron un cuello. La proximidad de interacción entre participantes hace que el receptor aparezca duplicado mediante el clítico correferencial de dativo le. En tanto del frame del sustantivo cuello se activa una escena en la que se visualiza un tipo específico de asesinato, matar a alguien cortándole el cuello (cortarle el cuello a una gallina, por ejemplo). La interpretación parece 
depender del contexto: en ocasiones alude a matar a alguien, pero a veces el contexto nos remite a la idea de excluir, o eliminar a alguien. Al igual que con dar cuerpo, dar cuello ya solo tiene lectura figurada. El sentido figurado proviene del marco conceptual de cuello asociado a prácticas sociales de castigo. Y la progresión construccional sigue los mismos cánones que las anteriores. Primero hay una lectura figurada del cuello concreto, luego hay una segunda extensión en la que afecta al participante en pleno. La Figura 5 esquematiza estas construcciones: la esfera de la izquierda representa al agente/sujeto, la esfera de la derecha representa el foco de la estructura que es el receptor porque aquí recae la acción de la construcción dar cuello. La flecha representa la fuerza que se ejerce para transformar al receptor, ya no representa una transferencia; en este caso también es por ello que podemos decir que hay un debilitamiento semántico del verbo dar, lo que se transfiere es una energía transformadora, no un objeto.

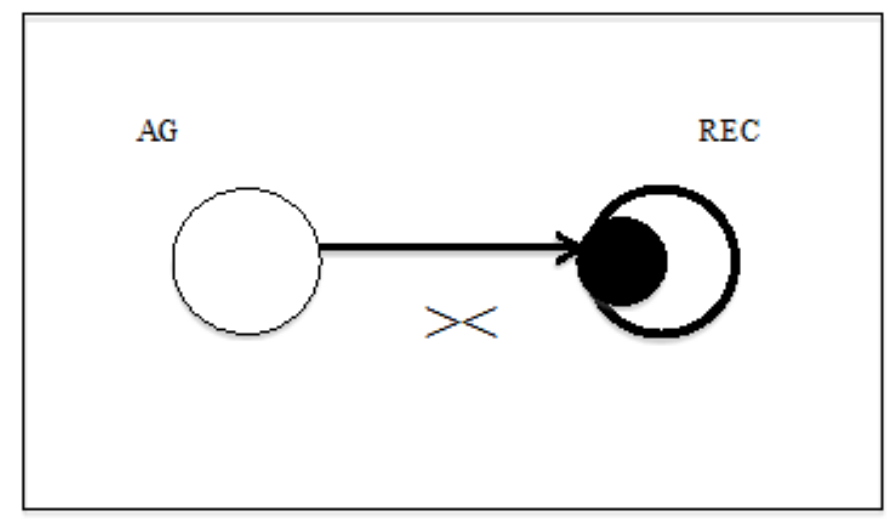

Figura 5: Dar cuello. Debilitamiento de la transferencia 
¿DAR la mano o darle Cuello? Construcciones metafóricas con SUSTantivos Corporales Alma Rocío Guzmán Herrera

\section{CONSTRUCCIONES ORIENTACIONALES}

En nuestro corpus resalta otro conjunto de ejemplos que expresan más que la funcionalidad del sustantivo de la parte del cuerpo involucrada en la construcción, su orientación física. Los ejemplos de (10) dar la cara y (11) darle la espalda a alguien / a algo muestran un paso más en el proceso de desemantización del verbo dar; en estos usos de dar más un sustantivo de referencia anatómica (cara y espalda) lo que se perfila es la orientación del cuerpo. Se parte de la conceptualización canónica de la comunicación oral en que hablante y oyente pueden establecer contacto visual y de ahí se dan extensiones en que el participante se dirige hacia un punto con capacidad de respuesta. Una vez más, el carácter inalienable de los sustantivos anatómicos cara y espalda como representantes de la orientación corporal impide toda lectura de transferencia literal y sólo activa sentidos figurados, sin embargo dar preserva la representación esquemática de trayectoria que implica toda transferencia, para garantizar las lecturas orientacionales, como en 10 :

(10a) Ha habido actuaciones excelentes como la de Soraya Jiménez o los propios caminantes, que dieron la cara por nuestro país, pero podemos y debemos aspirar a cosas mejores debido a que es una demanda a nivel nacional para nuestro deporte representativo. [CREA. 2000. México. Prensa. Excélsior].

(10b) Claudio continúa sumando partidos internacionales a la casaca verde. Lleva 164, de los cuales comentó ha tenido que dar la cara 
por compańeros suyos en relación con las percepciones, empero en esta ocasión subrayó que en lo profesional el dinero, en este momento, para muchos pasa a segundo término porque, ratificó, “lo más importante es la clasificación al mundial”[CREA. 2001. México. Prensa. Excélsior].

Dar la cara es "enfrentar", o "representar a otro". En (10a) "los deportistas" representan a nuestro país. En (10b) el sujeto se pone en lugar de un conjunto de personas ante las autoridades. De nuevo, es el marco conceptual, más que la parte corporal, lo que se activa. De la transferencia se hereda un agente cuya disposición física se dirige a otro participante. En (10a) el significado es de representación. El sustantivo se fija en singular con determinante definido. Es imposible decir *dar una cara/*dar cara. Lo que ofrece el frame del sustantivo cara es la interacción comunicativa, una orientación cara a cara. La idea de trayectoria se reinterpreta como orientación. La parte anterior del cuerpo ofrece los rasgos identitarios del participante. De ello se desprende su toma de responsabilidad por actos ya sea propios o ajenos. La construcción involucra además una conceptualización de dinámica de fuerzas por cuanto presupone la existencia de una fuerza oponente. Uno da la cara ante un posible adversario o agresor. Como se ve en (10b), el agente se enfrenta ahora a una fuerza opositora. En esta construcción la noción de control potencial del receptor se pierde totalmente en favor de la toma de responsabilidad del agente; sin embargo, su presencia como fuerza opositora prevalece. 
¿Dar la mano o darle cuello? Construcciones metafóricas con sustantivos corporales Alma Rocío Guzmán Herrera

En resumen, existe una orientación comunicativa, lo que se da, lo que se transfiere, es lo que ofrece la comunicación: la orientación de la cara según se conceptualiza el encuentro canónico de la comunicación y el verbo dar impone la direccionalidad implícita en toda transferencia.

Interesante es lo que sucede en los ejemplos de (11) que corresponden a darle la espalda a alguien o algo. Evidentemente, se trata del mismo marco conceptual orientacional ahora en su representación inversa:

(11a) Y entonces Teresa, toda ojos, dientes separados, trenzas ralas, toma -muy a su pesar- la batuta del mando. CORAL: Yo... Don Dimas... Teresa regresa al sofá dándole la espalda a la madre y tirando el conejo al piso. [CREA. 1997. México. Prensa].

(11b) ¡En toda la familia digna la ociosidad debe estar terminantemente prohibida! -y al decir esto dio un golpe en la mesa que me hizo saltar-. Por ningún motivo deberá permitirse desertar del colegio o darle la espalda a las responsabilidades. [CREA. 1992. México. Cuauhtémoc Sánchez, Carlos. Un grito desesperado. Ediciones Selectas Diamante].

(11c) Hoy nadie puede darle la espalda a la globalización. Darle la espalda a la globalización no hace a un país mejor, o peor, darle la espalda a la globalización sería un error histórico. La globalización no puede ser evadida. [CREA. 1997. México. Oral. Cámara de Senadores]. 
El significado de (11a) es orientacional, corresponde a la acción de voltear el cuerpo mostrándole la espalda al receptor con lo cual se niega la posibilidad de la comunicación. El significado de (11b, c) es metafórico, en (11b) "no se cumplen con las responsabilidades", en tanto en (11c) "no se apoya", "no se ayuda”. Esto es posible porque, como ya hemos visto a lo largo del trabajo, opera el frame más que la parte del cuerpo en sí. Al partir del encuentro canónico de la comunicación cara a cara, la espalda le impone ciertas restricciones al verbo dar. Aunque permanece la base de la transferencia, el marco conceptual solo aporta orientación canónica ahora negada. De la construcción de transferencia se hereda un agente que provoca que un receptor se vea afectado negativamente cuando el agente adopta una posición corporal que niega el acceso visual y la posibilidad de comunicación (11a). En $(11 b, c)$ la trayectoria permanece como ruta potencial no satisfecha, de manera que prevalece la noción de orientación de sujeto. Se pierde la noción de control por parte del receptor y sólo queda en la base el efecto negativo de que la ruta orientacional no se cumpla. Formalmente la estructura se conserva, el sustantivo se fija en singular con determinante definido. Es imposible decir: *dar una espalda/*dar espalda. Quizá la prominencia de la cara y la espalda como representantes metonímicos de la orientación del cuerpo hacia adelante y hacia atrás exija el empleo del artículo definido.

En la Figura 6 se muestran esquemáticamente las construcciones: dar la cara y dar la espalda. Las esferas de la izquierda representan al emisor del evento comunicativo, en tanto las esferas de la derecha representan al receptor; las flechas que se desprenden de las esferas indican la orientación 


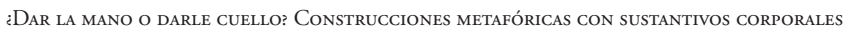
Alma Rocío Guzmán Herrera

María del Refugio Pérez Paredes

Ricardo Maldonado

de la parte frontal del cuerpo, el lugar hacia donde se expone la cara. Los ángulos $(><$ representan los casos en que hay dinámica de fuerzas.

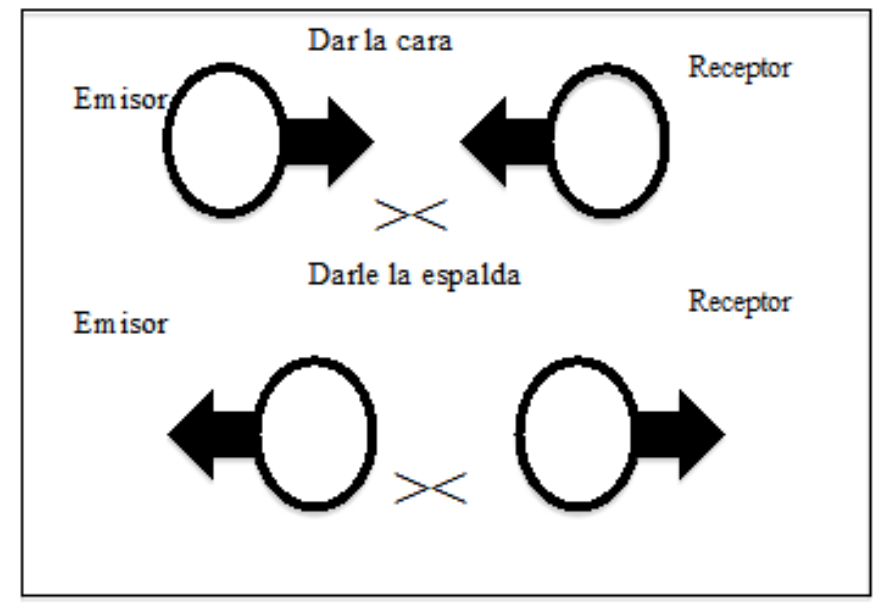

Figura 6: Construcciones orientacionales

\section{DESEMANTIZACIÓN DE DAR CON PARTES DEL CUERPO}

Dar es un verbo de transferencia; una transferencia canónica ocurre cuando una entidad prototípicamente humana transfiere un objeto, concreto o abstracto, al dominio de otro participante, el cual funge como nuevo poseedor del objeto transferido: darle un regalo a María. Hemos sostenido que el sustantivo corporal impone su marco conceptual a la nueva construcción. Proyecta rasgos funcionales o rasgos asociados que generan un proceso de desemantización en el verbo dar, dada la imposibilidad de que la parte inalienable sea literalmente transferida. En los ejemplos que 
corresponden a darle la mano a alguien, darle el pecho al nińo, darle las nalgas a alguien, la transferencia es parcial y momentánea ya que los sustantivos corporales, por ser inalienables, pasan momentáneamente a la esfera del receptor para propiciarle una afectación positiva, esta transferencia momentánea puede ser concreta o abstracta. Si es abstracta permite la entrada del significado metafórico y las propiedades de inalienabilidad se debilitan de manera que el evento deja de ser momentáneo. En el caso de estos mismos ejemplos en las construcciones genéricas se muestra la transferencia debilitada al ser el receptor un participante esquemático que no está explícito en la construcción: dar pecho (amamantar), dar la mano (ayudar), dar las nalgas (ceder sin respeto propio). En las construcciones de imposición de estructura (darle cuerpo a algo, darle cuello a alguien) el significado de dar, está aún más deslavado ya que no hay transferencia propiamente dicha de un objeto concreto a la esfera del receptor, lo que se transfiere es una asociación abstracta, es una fuerza que modifica al receptor que funge más como un paciente. El último estado de desemantización del verbo dar que se presenta en estas construcciones es con los ejemplos orientacionales (dar la cara, dar la espalda) que provienen del esquema de orientación comunicativa; en el primero, lo que se ofrece es la orientación corporal según lo impone el perfil de la parte del cuerpo: enfrentamiento para cara ya que coincide con el evento comunicativo canónico y su negación para espalda según presenta las propiedades opuestas. Ahora bien, aunque el proceso de desemantización de dar es innegable, la preservación de la estructura esquemática del verbo no es menos patente. La ruta conceptual que va del 
sujeto emisor al receptor no puede dejar de estar presente. Ella garantiza que, incluso en las lecturas más abstractas, haya una proyección de la fuente a la meta a lo largo de una trayectoria. Si bien los puntos de contacto se deslavan y la consecución de una trayectoria se transforma en transmisión de energía o en orientación, no habría manera de entender ninguna de estas expresiones sin esa base direccional. Si bien es cierto que el objeto corporal de cada construcción impone las lecturas aquí expuestas, no se puede afirmar que dar se haya limitado a ser un verbo de apoyo o un verbo ligero. Dar impone una conceptualización, que si bien es esquemática, constituye la base para la formación de transferencias cada vez más abstractas.

El cuadro de la Figura 7 representa la esquematización de cada una de las construcciones analizadas en este trabajo y la progresión de desemantización del verbo dar. El esquema debe leerse de arriba hacia abajo. Del lado izquierdo están las estructuras más cercanas a la construcción canónica de transferencia, y del lado derecho las más alejadas al significado prototípico de la transferencia. De la transferencia de un objeto en 7.1 se transfiere la funcionalidad asociada a la parte corporal en 7.2 (el círculo punteado) y de ahí a sus representaciones genéricas en 7.3 (con el círculo grande de dominio ahora en la línea punteada). En 7.4 tenemos la transferencia y la imposición de estructura en que la forma de A se impone sobre B. Por su parte en 7.5 la dinámica de fuerzas obvia la noción de transferencia e impone un cambio en la parte corporal del receptor. Finalmente, en 7.6, en lugar de transferencia sólo prevalece la trayectoria que licencia una representación orientacional asociada a la cara o a la espalda de un cuerpo cualquiera. 


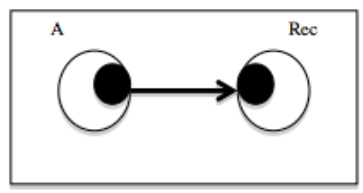

7.1 Transferencia canónica:darle un regalo a María

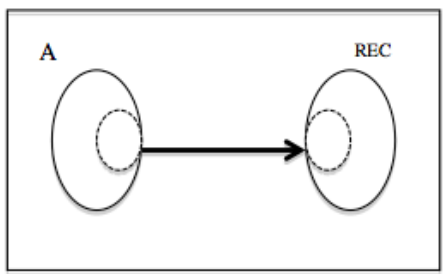

7.2 Darle una parte del cuerpo a alguien: darle la mano, el pecho, las nalgas a alguien.

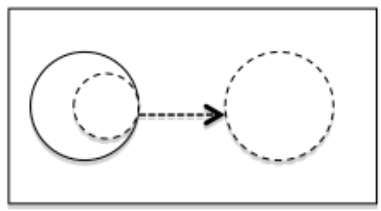

7.3 Genéricos: dar la mano, el pecho, las nalgas.

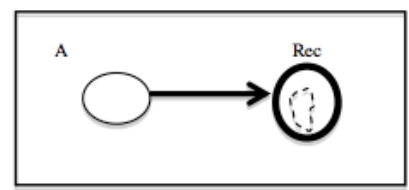

7.4 Darle cuerpo algo

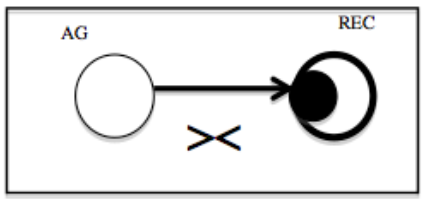

75 Darle cuello a alguien

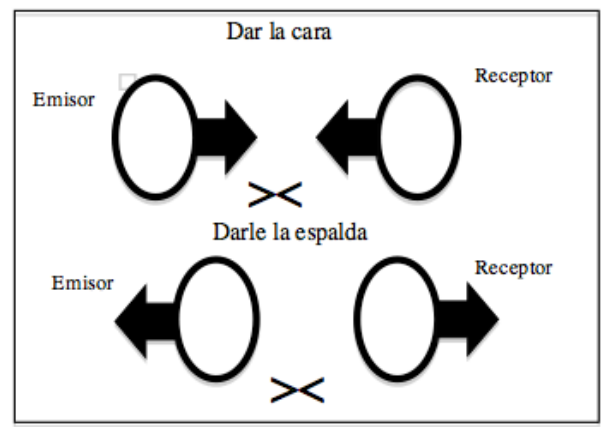

7.6 Esquema orientacional de interacción comunicativa dar la cara, dar la espalda

Figura 7: Esquemas de la progresión del proceso de desemantización del verbo dar con sustantivo de referencia anatómica

\section{CONCLLSIONES}

En este trabajo hemos intentado proponer dos ideas fundamentales. En primer lugar, que la polisemia de una forma lingüística presupone distintos 
¿Dar la mano o darle cuello? Construcciones metafóricas con sustantivos corporales Alma Rocío Guzmán Herrera

procesos de desemantización que, sin embargo, preservan su estructura esquemática. En el caso de dar se proyecta en forma consistente una trayectoria de fuente a meta que opera de manera cada vez más abstracta. Esta preservación de significado permite entender que, en estas construcciones, dar no opera como verbo ligero, sino que sigue siendo una forma léxica que une su significado de base con el de la parte corporal, primero para formar significados literales asociados a dicha parte y, luego, para proyectar lecturas figuradas con distintos grados de abstracción. Los significados figurados se activan a partir de distintas partes del marco conceptual que cada parte corporal evoca. La segunda propuesta tiene que ver con los niveles en que opera la metonimia. En su nivel básico, la parte corporal representa metonímicamente, ya sea, alguna de sus funciones, ya alguna asociación que se activa dentro de su complejo marco conceptual. En un segundo nivel, las proyecciones metonímicas operan a nivel construccional (Flores y Maldonado, 2016). Unas construcciones se conectan con otras para motivar distintos tipos de extensiones y elaboraciones. Para ello, es necesario que la representación esquemática de transferencia de dar se mantenga en la base de toda construcción. Sobre ella se despliega un conjunto de especificaciones conceptuales impuestas por la activación del marco conceptual asociado a cada parte del cuerpo. Y tales especificaciones permiten identificar un desarrollo conceptual que va asociado con distintos grados de desemantización. La pérdida de rasgos de la transferencia licencia la formación de representaciones de conceptos cada vez más abstractos como los que esquematizan en (12): 
(12) Transferencia A-B > contacto corporal A-B > acción asociada proyectada $\mathrm{a} \mathrm{B}>$ imposición de estructura en $\mathrm{B}>$ afectación de $\mathrm{B}$ $>$ orientación de A hacia un punto difuso.

La conexión entre construcciones permite identificar rutas conceptuales que van de lo más concreto a lo más abstracto, preservando siempre una base de trayectoria que se actualiza en ámbitos distintos, según los marcos conceptuales de cada parte del cuerpo, nos transporta a los mundos en que el cuerpo viaja dentro de nuestra vida cotidiana.

\section{REEERENCIAS BiBLIOGRÁFICAS}

Alonso Ramos, Margarita. Las construcciones con verbo de apoyo. Madrid: Visor Libros, 2004.

Chappel, Hilary y McGregor, William. "Prolegomena to a theory of inalienability", en Hilary Chappel y William McGregor, editores, The grammar of inalienability: A typological perspective on body parts terms and the part-whole relation. BerlinNew York: Mouton de Gruyter, 1996.

Charteris-Black, Jonathan. "Cultural Resonance in English and Malay Figurative Frases: The Case of the Hand”. In: Janet Cotterill y Anne Ife (eds.). Language and Bounderies, Londres y Nueva York: British Association for Applied Linguistics y Continuum,2001, 151-170.

De León, Lourdes. Body Parts and Location in Tzotzil: A Case of Gramaticalization, trabajo presentado en el taller "Pace Conceptualization in Mesoamerican Languages", Cognitive Anthropology Research Group. MPI: Nijmegen, diciembre, 1991.

De León, Lourdes. "Body Parts and Location in Tzotzil: Ongoing Grammaticalization”. In: STUF-Language Typology and Universals, 45 (1-4), 1992, 570-589. 


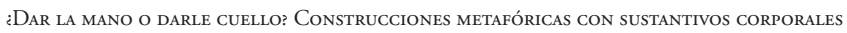

Alma Rocío Guzmán Herrera

María del Refugio Pérez Paredes

Ricardo Maldonado

De León, Lourdes. "Shape, Geometry and Location: The Case of Tzotzil Body Part Terms". In: CLS 29: Papers from the Para session on Conceptual Representations, Chicago: Chicago Linguistics Society, 1993, 77-90.

Fauconnier, Gilles y Turner, Mark. The Way We Think. Nueva York: Basic Books, 2002.

Fillmore, Charles."Frame Semantics". In: Linguistic Society of Korea, Linguistics in the Morning Calm, Seúl: Hanshin, 1982, 111-138.

Fillmore, Charles. "Frames and the Semantics of Understanding. In: Quaderni di Semantica 6 (2), 1985, 222-253.

Flores, Marcela y Maldonado, Ricardo. "Metonimia sintáctica en construcciones de transferencia”. In: Nueva Revista de Filología Hispánica, El Colegio de México, vol. 63, núm.1,2016, 76-94.

Goldberg, Adele. Construction. A Construction Grammar Approach to Argument Structure. Chicago: The University of Chicago Press, 1995.

Goldberg, Adele."Constructions: A New Theoretical Approach to Language”. In: Trends in Cognitive Science, University Illinois, 2003.

Goldberg, Adele. Constructions at Work. The Nature of Generalization in Language. Oxford: Oxford University Press, 2006.

Goschler, Juliana."Embodiment and Body Metaphors". In: Metaphorik. de, 09, 2005, 33- 52.

Heine, Bernd. Possesion. Cognitive Sources, Forces and Gramaticalization. Cambridge. Cambridge University Press, 1997.

Heine, Bern, Claudi, Ulrike y Hünnemeyer, Friederike. Grammaticalization: A Conceptual Framework. Chicago: University of Chicago Press, 1991.

Johnson, Mark. El cuerpo en la mente: fundamentos corporales del significado, la imaginación y la razón. Madrid: Debate, 1992. [Traducción de The Body in the Mind: The Bodily Basis of Meaning, Imagination and Reason, Chicago: The University of Chicago Press, 1987]. 
Julià Luna, Carolina y Ana Paz Afonso. "Somatismos con la voz mano y verbos de desplazamiento en el Diccionario de Autoridades: estudio histórico y cognitivo". In Actas del VIII Congreso Internacional de Historia de la Lengua Española, 2012, 1445-1459.

Lakoff, George. Metaphors We Live By. Chicago y Londres: The University of Chicago Press, 1980.

Lambert, Silke. Beyond Recipients: Towards a Typology of Dative Uses. Tesis de doctorado. University at Buffalo, State University of New York, Nueva York: 2010 .

Langacker, Ronald W. Foundations fo Cognitive Grammar Vol.1 Theorerical Prerequisites. Stanford. Stanford University Press, 1987.

Langacker, Ronald W. "Subjectification". In: Concept, Image and Symbol: The Cognitive Basis of Grammar, Berlín Nueva York: Mouton de Gruyter,1991, 315-342.

Levinson, Stephen."Language and Space". In: Anual Review of Anthropology, 25, 1996a, 353-382.

Levinson, Stephen."Frames of Reference and Molyneux's Question: Crosslinguistic Evidence”. In: Bloom, Paul, Mary A. Peterson, Lynn Nadel y Merril F. Garrett (eds.). Language and Space, Cambridge, Mass.: MIT Press, 1996b,109-169.

Maclaury, Robert E. "Zapotec Body-Part Locatives: Prototypes and Metaphoric Extensions”. In:International Journal of American Linguistics 55, 1989, 119-154.

Maldonado, Ricardo. "Objective and Subjective Datives". In: Cognitive Linguistics vol.13, núm. 1, 2002, 1-65.

Márquez Linares, Carlos. La polisemia en el campo léxico EL CUERPO HUMANO: un estudio contrastivo inglés-español. Córdoba: Universidad de Córdoba, 1998.

Márquez Linares, Carlos y Moreno Ortiz, Antonio. "Fraseología Comparada mediante el Uso de Córpora Textuales: el Caso de Mano/Hand". In: Actas del III Simposio Andaluz de Lingüistica General: SLS'99,1999. 


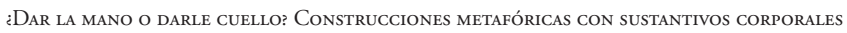

Alma Rocío Guzmán Herrera

María del Refugio Pérez Paredes

Ricardo Maldonado

Pérez Paredes, Ma. del Refugio. “Caracterización semántico-sintáctica de las partes del cuerpo en español". Tesis de doctorado. Universidad Nacional Autónoma de México, México: 2009.

Seiler, Hansjakob. Possession as an Operational Dimension of Language. Tübingen: Gunter Narr (Language Universal Series, 2), 1983.

Svorou, Soteria. The Grammar of Space. Amsterdam/Philadelphia: John Benjamins, 1994.

Talmy, Leonard. "Force Dymanics in Language and Thougth". In: Papers from the Regional Meetings, Chicago Linguistics Society, University of Chicago, 21, 1985, 293-337.

Talmy, Leonard. "Force Dymanics in Language and Thougth". In: Toward a Cognitive Semantics, vol.1: The MIT Press, 2000.

Vandeloise, Claude. L'Espace en français.París: Editions du Seuil, 1986.

Vuksan, Iva. "Somatismos mano, dedo y puño en la fraseología española, italiana y croata”. In: https://repozitorij.unizd.hr/islandoralobject/unizd:54, 2016,consultada el 25 de abril de 2019. 